\title{
Effect of a Single Dialysis Session on Cognitive Function in Chronic Kidney Disease Stage 5 Hemodialysis Patients
}

Andi Rahmat Hidayat ${ }^{1}$, Haerani Rasyid ${ }^{2}$, Syakib Bakri ${ }^{2}$, Hasyim Kasim² ${ }^{2}$, Saidah Syamsuddin ${ }^{3}$, Arifin Seweng ${ }^{4}$

1. Departement of Internal Medicine, Faculty of Medicine, Hasanuddin University

2. Division of Nephrology, Department of Internal Medicine, Faculty of Medicine, Hasanuddin University

3. Departement of Psychiatric, Faculty of Medicine, Hasanuddin University

4. Departement of Biostatistics, Faculty of Public Health, Hasanuddin University

Editor:

Rully M.A. Roesli

Received 7 April 2019, revised 1 July 2019, accepted 17 July 2019, published 1 August 2019

\begin{abstract}
Background: The incidence of cognitive impairment (CI) has been widely reported in various studies among chronic kidney disease (CKD) patients. Many factors influence cognitive function including the hemodialysis (HD) process itself. There is much evidence that a single HD session brings about changes in the cognitive status of patients, but just a few studies assessing whether cognitive performance varies with dialysis.
\end{abstract}

Aim: To know the effect of single dialysis session on cognitive function in HD patients.

Method: Sixty medically stable CKD stage 5 patients on HD maintenance for at least three months were enrolled. Cognitive testing performed thrice, 1-2 hour prior to dialysis (T1), 3-4 hour into the session (T2) and 24 hour after the session (T3) using a wellvalidated neuropsychological test battery, Montreal Cognitive Assessment (MoCA) Indonesian version which assess the domain of cognitive function including visuospatial, executive function, naming, memory, attention, language, abstraction, recall, and orientation.

Result: Subjects' mean age was 45,45 $\pm 11,28$ years, dialysis vintage $10,12 \pm 11,88$ months, 44 patients $(73,3 \%)$ had CI at baseline. Cognitive function decline during dialysis (T2) (MoCA INA score 21,65 to 19,67, $p<0.001)$ and visuospatial, executive function, attention, language and recall was impaired during dialy- sis. Cognitive function reached its best 24 hour after dialysis (MoCA INA score 23,65, $p<0.001$ ) and all the domain of cognitive function was improved except naming that didn't change over the dialysis session.

Conclusion: There is an effect of single HD session on global cognitive function where executive function, attention, language, and recall deteriorated during HD while abstraction and orientation didn't change. All cognitive domains were recovered 24 hours after HD except naming that didn't change from baseline throughout the whole process.

Keywords: cognitive function, chronic kidney disease, hemodialysis

\section{Corresponding author :}

Email : dr.1andi2rahmat1990@gmail.com (Hidayat, AR), phone : +6281356308094

\section{Introduction}

Chronic kidney disease (CKD) is a major public health problem varying in severity from asymptomatic to end stage renal disease (ESRD) requiring hemodialysis (HD). ${ }^{1}$ Patients with CKD are frequently associated with neurological complication. Common neurological 


\section{Participants and Setting}

The design of this study was cross-sectional. Patients were selected among those attending the HD unit of Dr. Wahidin Sudirohusodo General Hospital, Makassar from June - October 2018. Inclusion criteria were patients over the age of 18 years old, medically stable, and willing to participate in the research, being on HD maintenance for at least 3 months, twice to thrice a week. Exclusion criteria were patients over the age of 60 years old because dementia is reported common over this age, unconscious, vision and hearing impairment, unable to read and to write, severe mental disorder, and consuming narcotics, psychotropic, and addictive drugs.

\section{Neuropsychological Assessment and Clinical Variables}

Cognition was assessed in a quiet and spacious room with adequate lighting and using a screen to isolate patients for privacy. Cognitive test was done using a well validated neuropsychological test, the MoCA INA tool. ${ }^{18,19}$ It assess 8 cognitive domains, generating a score of between 0 to 30 - Visuospatial/executive function (5), naming (3), memory (0), attention (6), language (3), abstraction (2), delayed recall (5) and orientation (6). Cognitive impairment was defined as MoCA INA score $<26$.

Cognitive test was done thrice, T1 was done 1-2 hour before the start of HD, T2 was done 3-4 hour into the session in the same day of T1, and T3 was done 24 hours after the HD session. For each assessment, the patients were allowed up to 30 minutes. All patients were dialyzed in the morning and afternoon, no medications were administered during dialysis except paracetamol, erythropoietin, and blood transfusion if required.

Patients who were the subject of the study underwent an examination starting with anamnesis to get the sociodemographic details (age, sex, and years of education), medical history, current medication, and comorbidities. Clinical data also included dialysis vintage, duration of each dialysis session, blood flow rate (QB), ultrafiltration volume (UF). We also did physical examinations including pre- and post-dialysis body weight, pre- and intra-dialysis blood pressure (BP). We also obtained some laboratory testing including hemoglobin $(\mathrm{Hb})$, plasma glucose, albumin, urea and creatinine, and electrolyte (all taken pre dialysis except for urea that was taken also at the end of the dialysis session to calculate 28 complications in CKD include stroke, cognitive impairment $(\mathrm{CI})$, encephalopathy and peripheral neuropathy. ${ }^{2,3}$ Cognitive impairment in patients with CKD are frequent and show increasing prevalence rates. Several risk factors such as uremia, anemia, fluid and electrolyte disorder, related comorbidities include hypertension (HT), diabetes mellitus (DM) and cerebrovascular diseases have been linked to cognitive decline. ${ }^{4-8}$

HD process itself has also been suggested as the potential cause of CI. Potential HD-specific mechanisms include acute fluid shift, dialysis disequilibrium syndrome and brain micro-bleeding due to anticoagulant during dialysis. However, there are also biochemical change induced by HD that potentially lead to cognitive improvement including uremic toxin elimination, correction of fluid and electrolyte disorder and partial correction of anemia. This mechanism possibly cause a fluctuation of cognitive function over a single HD session. ${ }^{9-11}$

Cognitive function is needed to access health services, process, understand, and recall written and spoken information and assimilate and express decisions about health care. ${ }^{12}$ Impaired cognition has been linked to reduced health literacy, decreased medication adherence, impaired physical and mental health, and greater risk for death. ${ }^{12-14}$ Therefore, even when cognitive improvement is temporary, such as after dialysis or between dialysis, it is important to sustain a good quality of life. ${ }^{11}$

There have been few studies examining cognitive function following a single dialysis session. The majority of studies had established that cognitive performance of HD patients was best approximately 24 hours after the last HD session compared to shortly before the session. ${ }^{15,16}$ To our knowledge, there was just one study with a small sample size that conducted cognitive tests during dialysis and at other times to measure acute variations in cognitive function during the dialysis cycle. ${ }^{17}$ In addition, there was no study assessing the cognitive function of HD patients in Indonesia in recent years.

Hence the aim of this study was to assess the effect of a single HD session on cognitive function using the Indonesian version of well-validated neuropsychological test battery, Montreal Cognitive Assessment (MoCA INA).

\section{Materials and Methods}

InaKidney | Vol. II | Is. 2| May-Aug 2019 
urea reduction rate [URR] and Kt/V). The protocol of the study was informed to all subjects regarding the risks and benefits of the study. Informed consent was acquired from all subjects.

\section{Result}

\section{Subject characteristic}

Sixty CKD stage 5 patients on maintenance HD completing all three cognitive testing were recruited. The mean age was $45,45 \pm 11,28$ years, 31 patients $(51,7 \%)$ were male, 41 patients $(68,3 \%)$ with education level $\leq 12$ years, dialysis vintage $10,12 \pm 11,88$ months, 50 patients $(83,3 \%)$ with non adequate HD. Socio-demographic and medical characteristics of the study participants are shown in table 1 and 2.

In this study, mean change of systolic BP $-1,33 \pm 12,55$ $\mathrm{mmHg}$, mean change of diastolic BP $-3,67 \pm 10,8$ $\mathrm{mmHg}, 10$ patients $(16,7 \%)$ had hypotension (systolic BP drop $\geq 20 \mathrm{mmHg}$ or MAP drop $>10 \mathrm{mmHg}$ ) during dialysis. Mean change in bodyweight over dialysis $-1,55 \pm 0,70 \mathrm{~kg}$. Blood flow rate during dialysis $120-300 \mathrm{ml} / \mathrm{min}$ (mean $177,17 \pm 26,69 \mathrm{ml} / \mathrm{min}$ ), ultrafiltration volume $500-3.500 \mathrm{ml}$ (mean $1.798 \pm 708,18$ $\mathrm{ml}$ ), range of $\mathrm{Kt} / \mathrm{V} 0,24-2,06$ (mean $0,94 \pm 0,41$ ) while URR range from 15,46-97,17 (mean 52,67 $\pm 17,24 \%$ ).

Table 1. Subject Characteristic (n=60)-Part 1

\begin{tabular}{lllc}
\hline Variable & & $\mathbf{n}$ & $\mathbf{\%}$ \\
\hline Sex & Men & 31 & 51,7 \\
& Women & 29 & 48,3 \\
\hline Age (years) & $18-40$ & 17 & 28,3 \\
& $41-60$ & 43 & 71,7 \\
\hline Education & $<=12$ & 41 & 68,3 \\
(years) & & & \\
& $>12$ & 19 & 31,7 \\
\hline Dialysis Vin- & $<6$ & 33 & 55,0 \\
tage & & & \\
(months) & $6-12$ & 27 & 45,0 \\
HD Frequency & 3 & 45 & 75,0 \\
(time/week) & 2 & 15 & 25,0 \\
\hline Duration in HD & 4 & 56 & 93,3 \\
(hours) & 5 & 4 & 6,7 \\
\hline \hline
\end{tabular}

Table 2. Subject Characteristics-Part 2

\begin{tabular}{|c|c|c|c|c|}
\hline Variable & Min & Max & Mean & SD \\
\hline Age (years) & 18 & 60 & 45,45 & 11,28 \\
\hline Dialysis Vintage & 3 & 60 & 10,12 & 11,88 \\
\hline Pre HD Weight (kg) & 35 & 85 & 54,62 & 9,96 \\
\hline Post HD Weight (kg) & 34 & 83 & 53,07 & 9,86 \\
\hline $\begin{array}{l}\text { Change in Weight } \\
(\mathrm{kg})\end{array}$ & -3 & 0 & 1,55 & 0,70 \\
\hline $\begin{array}{l}\text { Pre HD Blood Pres- } \\
\text { sure }(\mathrm{mmHg})\end{array}$ & & & $150,83 / 83,67$ & $18,80 / 13,65$ \\
\hline $\begin{array}{l}\text { Intra HD Blood } \\
\text { Pressure (mmHg) }\end{array}$ & & & $149,5 / 80$ & $21,10 / 14,61$ \\
\hline $\begin{array}{l}\text { Change in Systolic } \\
\mathrm{BP}(\mathrm{mmHg})\end{array}$ & -30 & 30 & $-1,33$ & 12,5 \\
\hline $\begin{array}{l}\text { Change in Diastolic } \\
\mathrm{BP}(\mathrm{mmHg})\end{array}$ & -40 & 20 & $-3,67$ & 10,89 \\
\hline $\begin{array}{l}\text { Blood Flow Rate } \\
\text { (QB) (ml/men) }\end{array}$ & 120 & 300 & 177,17 & 26,69 \\
\hline $\begin{array}{l}\text { Ultrafiltration } \\
\text { Volume (ml) }\end{array}$ & 500 & 3500 & 1798,33 & 708,18 \\
\hline $\mathrm{Kt} / \mathrm{V}$ & 0,24 & 2,06 & 0,94 & 0,41 \\
\hline URR (\%) & 15,46 & 97,17 & 52,67 & 17,24 \\
\hline $\mathrm{Hb}(\mathrm{gr} / \mathrm{dl})$ & 5,1 & 11,0 & 8,04 & 1,30 \\
\hline Albumin (gr/dl) & 2,0 & 4,3 & 3,18 & 0,54 \\
\hline $\begin{array}{l}\text { Plasma Glucose } \\
(\mathrm{mg} / \mathrm{dl})\end{array}$ & 65 & 288 & 121,45 & 45,59 \\
\hline Sodium (mmol/1) & 126 & 146 & 138,23 & 4,43 \\
\hline Potassium (mmol/1) & 3,3 & 6,7 & 4,56 & 0,75 \\
\hline
\end{tabular}

\section{Cognitive test}

Forty four patients $(73,3 \%)$ had CI before the start of HD session (T1) (MoCA INA score < 26) while during HD (T2) the participant who had CI increased to 55 patients $(91,7 \%)$ and $24 \mathrm{hr}$ after HD (T3) the participant who had CI decreased to 37 patients $(61,7 \%)$ (Table 3$)$.

The total MoCA INA score T2 was significantly lower than T1 (19.67 to 21.65 ( $\mathrm{p}<0.001)$. Whereas T3 was significantly higher than T1 (23.65 to 21.65 ( $\mathrm{p}<0.001)$. (Table 4) A significant change was found in cognitive function in T2 compared to T1 $(p<0.001)$ where 11 out of 16 subjects $(68.8 \%)$ whose cognition changed from 
normal to abnormal in T2. While a significant change in cognitive function also found in T3 compared to T1 ( $p<0.05)$ where 7 out of 44 subjects $(15.9 \%)$ whose cognition changed from abnormal to normal after HD. (Table 5) Executive function, attention, language and recall was lower in T2 compared to T1 $(p<0.05)$, Abstraction and orientation weren't different between T1 and T2 $(p>0.05)$. All cognitive domains improved in T3 $(p<0.05)$ compared to T1 and T2 except naming that didn't change over the session. (Table 6)

Table 3. Distribution of Cognitive Impairment

\begin{tabular}{llll}
\hline Test time & Cognitive Function & n & \% \\
\hline T1 & Normal & 16 & 26,7 \\
& Abnormal & 44 & 73,3 \\
\hline T2 & Normal & 5 & 8,3 \\
& Abnormal & 55 & 91,7 \\
\hline T3 & Normal & 23 & 38,3 \\
& Abnormal & 37 & 61,7 \\
\hline \hline
\end{tabular}

Table 4. Comparison of Total MoCA INA Score

\begin{tabular}{cccc}
\hline Test Time & Mean & SD & $\boldsymbol{P}$ \\
\hline T1 & 21,65 & 5,32 & \\
T2 & 19,67 & 4,82 & 0,000 \\
T3 & 23,65 & 5,38 & 0,000 \\
\hline \hline
\end{tabular}

Table 6. Comparison of Cognitive Function Domains

\begin{tabular}{lccc}
\hline Cognitive Domains & Mean & SD & $\boldsymbol{p}$ \\
\hline Executive (T1) & 2,95 & 1,84 & \\
Executive (T2) & 2,52 & 1,74 & 0,000 \\
Executive (T3) & 3,20 & 1,85 & 0,001 \\
\hline Naming (T1) & 2,63 & 0,71 & \\
Naming (T2) & 2,63 & 0,71 & 1,000 \\
Naming (T3) & 2,63 & 0,71 & 1,000 \\
\hline Attention (T1) & 4,27 & 1,33 & \\
Attention (T2) & 3,57 & 1,18 & 0,000 \\
Attention (T3) & 4,68 & 1,31 & 0,000 \\
\hline Language (T1) & 1,92 & 0,89 & \\
Language (T2) & 1,73 & 0,84 & 0,040 \\
Language (T3) & 2,20 & 0,73 & 0,000 \\
\hline Abstraction (T1) & 1,15 & 0,73 & \\
Abstraction (T2) & 1,18 & 0,72 & 0,419 \\
Abstraction (T3) & 1,27 & 0,71 & 0,007 \\
\hline Recall (T1) & 2,90 & 1,49 & \\
Recall (T2) & 2,17 & 1,51 & 0,000 \\
Recall (T3) & 3,55 & 1,62 & 0,000 \\
\hline Orientation (T1) & 5,17 & 0,72 & \\
Orientation (T2) & 5,18 & 0,70 & 0,709 \\
Orientation (T3) & 5,45 & 0,70 & \\
\hline \hline
\end{tabular}

\section{Discussion}

We evaluated the cognitive function in CKD stage 5 patients before, during and after a single HD session. The results revealed that on general assessment of cognition, the patients had low score of cognitive functions (MoCA INA < 26) in pre, intra and post HD. Our data suggest that HD patients with CI is common as seen

Table 5. Change in Cognitive Function during and after HD

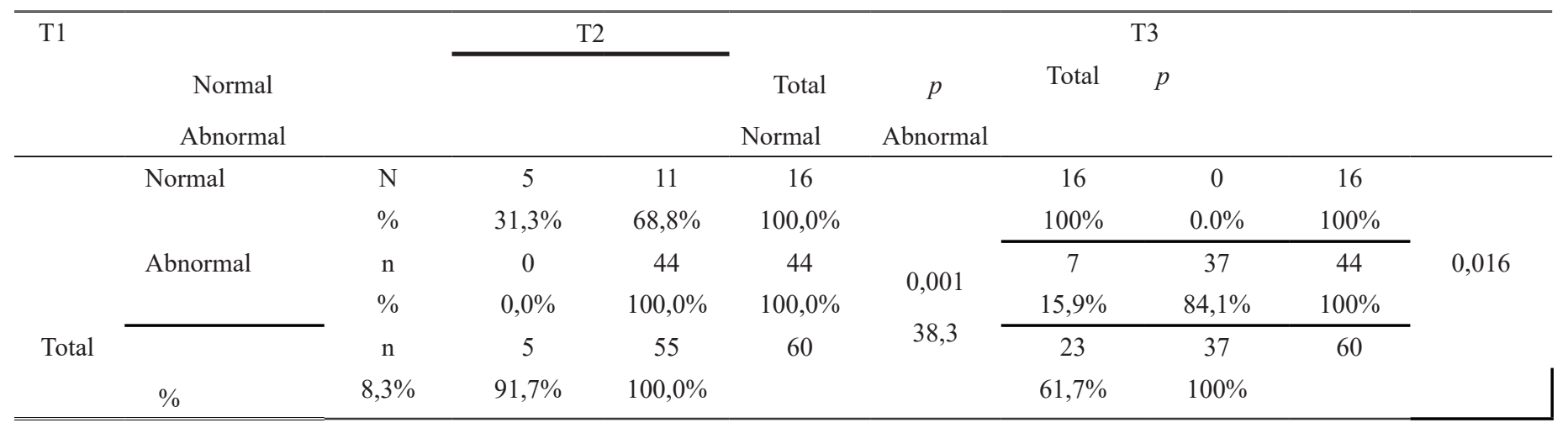


there were at least 44 patients $(73,3 \%)$ who had CI at the start of HD (baseline). Consistent with Dasgupta et.al who reported $76 \%$ patients had at least mild CI at the start of HD session and $15 \%$ had severe CI. ${ }^{20}$

In this study, we found a significant decline of cognitive function during HD in majority of patients as seen from MoCA INA score $(21,65 \pm 5,32$ to $19,67 \pm 4,82, p$ $<0.001)$ and also 11 out of 16 patients $(68.8 \%)$ whose cognition changed from normal to abnormal during HD $(p<0.001)$. A single HD session lead to cognitive improvement as seen from MoCA INA score $(21,65 \pm$ $5,32$ to $19,67 \pm 4,82$ to $23,65 \pm 5,38, p<0.001)$ and also 7 out of 44 patients $(15.9 \%)$ whose cognition changed from abnormal to normal after HD $(p<0.001)$. This shows an acute fluctuating change in cognition over a single HD session and cognitive impairment can be exacerbated by the HD process itself. ${ }^{21}$ One prior study had addressed similar questions regarding the acute variation in cognitive function over a single HD session. Murray et $\mathrm{al}^{17}$ performed cognitive testing in 28 HD patients at four different time periods: $1 \mathrm{hr}$ before, during (45-90 min from start), $1 \mathrm{hr}$ after, and 24-30 hr after. Consistent to our finding that the cognitive function being worst during HD and best the day after.

The relationship between CI and HD is still not fully understood and the etiology is thought to be multifactorial. ${ }^{22,23}$ Hemodynamic stress during HD lead to temporary deterioration of cognitive function which subsequently improves several hours after HD as an effect of uremic toxin elimination..$^{20,22,24}$ Hemodynamic stress during HD will be transmitted to and causes dysregulation of cerebral circulation. ${ }^{20,25}$ Fluid and electrolyte shift, intravascular volume loss during HD can also cause brain edema, decreased intracerebral pressure and perfusion to brain. ${ }^{9,26}$ And in the end, transient cerebral injury that occurs continuously will contribute to long-term CI in HD patients. ${ }^{20}$

In this study, we found there were deterioration of multiple cognitive domains during HD including visuospatial, executive function, attention, language, and recall. After $\mathrm{HD}$, we found an improvement of all cognitive domain except naming that didn't change over HD session. Consistent to our study, Murray et.al found deterioration in attention, memory and executive function during HD as well as Dasgupta et.al who found deterioration in attention, language, abstraction, and delayed recall. ${ }^{17,20}$
This study have a significant clinical implications. Cognitive impairment during HD is associated with impaired capacity to actively process and retain information. ${ }^{20}$ Providing information regarding health status, treatment plans, medication use, diet and other lifestyle changes is very important when patients have good attention, can remember the information communicated, plan and execute the steps needed to meet the goals of the treatment plan. ${ }^{11,27}$ Thus providing information to patients during HD may not be recommended especially after second half of the session because at that time it showed a significant deterioration in cognitive function.

\section{Limitation}

Our study has a number of limitations; firstly, MOCA-INA we used has good sensitivity in diagnosing cognitive disorders but cannot determine the degree of cognitive impairment. Secondly, the HD process itself may not be the only factor affecting the cognitive function in CKD patients. Further studies are needed to evaluate factors that affect the cognitive function in CKD.

\section{Conclusion}

There is an effect of single HD session on global cognitive function where executive function, attention, language, and recall were deteriorated during HD while abstraction and orientation didn't change. All Cognitive domains were recovered 24 hours after HD except naming that didn't change since the beginning

\section{References}

1. Weiner DE. Public Health Consequences of Chronic Kidney Disease. Clin Pharmacol Ther. 2009; 86(5): 566-9.

2. Bello AK, Alrukhaimi M, Ashuntantang GE, et.al. Complication of Chronic Kidney Disease: Current State, Knowledge Gaps, and Strategy for Action. Kid Int Supp. 2017; 7: 122-9.

3. Arnold R, Issar T, Krishnan AV, et.al. Neurological Complications in Chronic Kidney Disease. JRSM Cardiovasc Dis. 2016; 5: 1-13.

4. Etgen T. Kidney Disease as a Determinant of Cognitive Decline and Dementia. Alzheimers Res Ther. 2015; 7(1): 29-30.

5. Yaffe K, Ackerson L, Kurella M, et al. Chronic Kidney Disease and Cognitive Function in Older Adults: Findings from the Renal Insufficiency Co- 
hort Cognitive Study. J Am Geriatr Soc. 2010; 58: 338-45.

6. Bronas UG, Puzantian H, Hannan M. Cognitive Impairment in Chronic Kidney Disease: Vascular Milieu and the Potential Therapeutic Role of Exercise. BioMed Research Int. 2017; 1-10.

7. Bugnicourt JM, Godefroy O, Chilon JM, et.al. Cognitive Disorders and Dementia in CKD: The Neglected Kidney-Brain Axis. J Am Soc Nephrol. 2013; 24: 353-63.

8. Pereirea A, Weiner DE, Scott T, et.al. Cognitive Function in Dialysis Patients. American J Kid Dis. 2005; 45(3): 448-62.

9. Murray AM. Cognitive Impairment in the Aging Dialysis and Chronic Kidney Disease Populations: An Occult Burden. Adv Chronic Kidney Dis. 2008; 15(2): 123-32.

10. Seliger $\mathrm{S}$, Weiner. Cognitive Impairment in Dialysis Patients: Focus on the Blood Vessels. Am J Kidney Dis. 2013; 61(2): 187-90.

11. Elias M, Seliger S, Torres R. Improved Cognitive Performance after a Single Dialysis Session: Where Do We Go from Here?. Nephrol Dial Transplant. 2015; 30: 1414-17.

12. Wolf MS, Curtis LM, Wilson EA, et al. Literacy, Cognitive Function, and Health: Results of the LitCog Study. J Gen Intern Med. 2012; 27(10): 13007.

13. Nguyen HT, Kirk JK, Arcury TA, et al. Cognitive Function is a Risk for Health Literacy in Older Adults with Diabetes. Diabetes Res Clin Pract. 2013: 101(2): 141-7.

14. Campbell NL, Boustani MA, Skopelja EN, et.al. Medication Adherence in Older Adults with Cognitive Impairment: A Systematic Evidence-Based Review. Am J Geriatr Pharmacother. 2012; 10(3): 165-77.

15. Schneider S, Maleeki AK, Muller K, et.al. Effect of a Single Dialysis Session on Cognitive Functioning in CKD5D Patients: A Prospective Clinical Study. Nephrol Dial Transplant .2015; 30: 1551-9.

16. Griva K, Davenport A, Hankins M, et.al. Acute Neuropsychological Changes in Hemodialysis and Peritoneal Dialysis Patients. Health Psychology. 2003; 22(6): 570-8.

17. Murray AM, Pederson SL, Tupper DE, et.al. Acute Variation in Cognitive Function in Hemodialysis Patient: A Cohort Study with Repeated Measures. American J Kid Dis. 2007; 50(2): 270-27.

18. Rambe AS, Fitri FI. Correlation between the Montreal Cognitive Assessment-Indonesian version (MoCA-INA) and the Mini-Mental State Examina- tion (MMSE) in Elderly. Open Access Maced J Med Sci. 2017; 5(7): 915-9.

19. Panentu D, Irfan M. Uji Validitas dan Reliabilitas Butir Pemeriksaan dengan Montreal Cognitive Assesment Versi Indonesia (MoCa-INA). Jurn Fisio. 2013: 1: 55-67.

20. Dasgupta I, Patel M, Mohammed N, et.al. Cognitive Function Declines Significantly during Haemodialysis in a Majority of Patients: A Call for Further Research. Blood Purif. 2018; 45: 347-55.

21. Iyasere O, Brown EA. Cognitive Function before and after Dialysis Initiation in Adults with Chronic Kidney Disease-A New Perspective on an Old Problem?. Kid Int. 2017; 91: 784-6.

22. Tamura MK, Vittinghoff E, Hsu CY, et.al. Loss of Executive Function before and after Dialysis Initiation in Adults with Chronic Kidney Disease. Kidney Int. 2017 April; 91(4): 948-53

23. Odagiri G, Sugawar N, Kikuchi A, et.al. Cognitive Function among Hemodialysis Patients in Japan. Annals Gen Psych. 2011; 10(20): 1-5.

24. Dixit A, Dhawan S, Raizada A, et.al. Attention and Information Processing in End Stage Renal Disease and Effect of Hemodialysis: A Bedside Study. Ren Fail. 2013; 35(9): 1246-50.

25. Belik FS, Martin LC, Franco RJ. Cognitive Impairment in Chronic Kidney Disease. J Bras Nefrol 2014; 36(2): 116-7.

26. Tamura AM, Larive B, Unruh ML, et.al. Prevalence and Correlates of Cognitive Impairment in Hemodialysis Patients: The Frequent Hemodialysis Network Trials. Clin J Am Soc Nephrol. 2010; 5(8): 1429-38.

27. Tholen S, Schmaderer C, Kusmenkov E, et.al. Variability of Cognitive Performance during Hemodialysis: Standardization of Cognitive Assessment. Dement Geriatr Cogn Disord. 2014; 38 :31-8 
MONTREAL COGIITIVE ASSESMENT-Versi Indonesia (MoCA-Ina)

\section{VISUOSPASIALEKSEKUTIF}

(5)<smiles>c1ccccc1</smiles><smiles>CCOc1ccccc1</smiles>
Begin

(D)

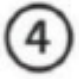

(3)

(C)

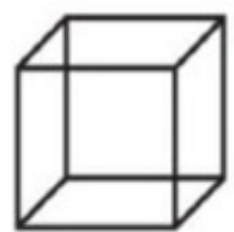

NAMA:

Pendidikan: Jen. Kelamin:

Tgl Lahir:

Tgl Pemeriksaan:

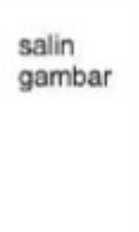

Gambar jam ( 11 lebih 10 menit)

(3 poin)

PENAMAAN

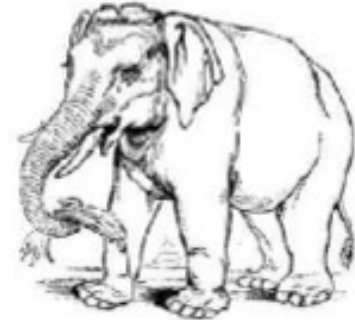

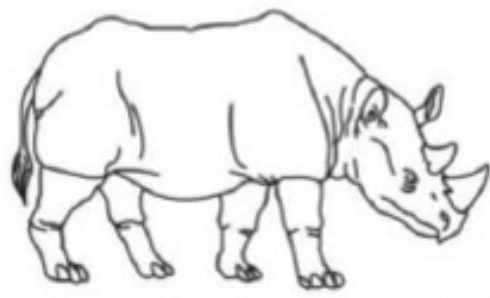

[ ]

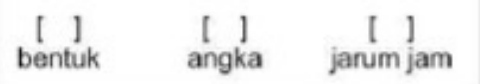

$\ldots / 5$

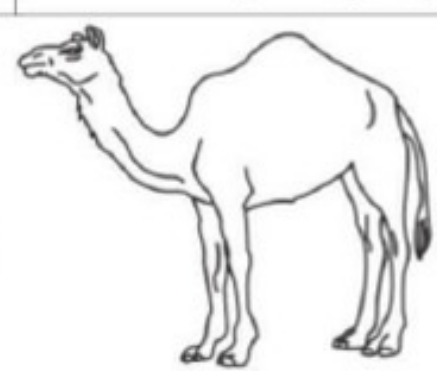

MEMORI

Baca kata berikut dan minta

subjek mengulanginya. lakukan 2 kali, meski berhasil pada percobaan ke-1. lakukan recall setelah 5 menit

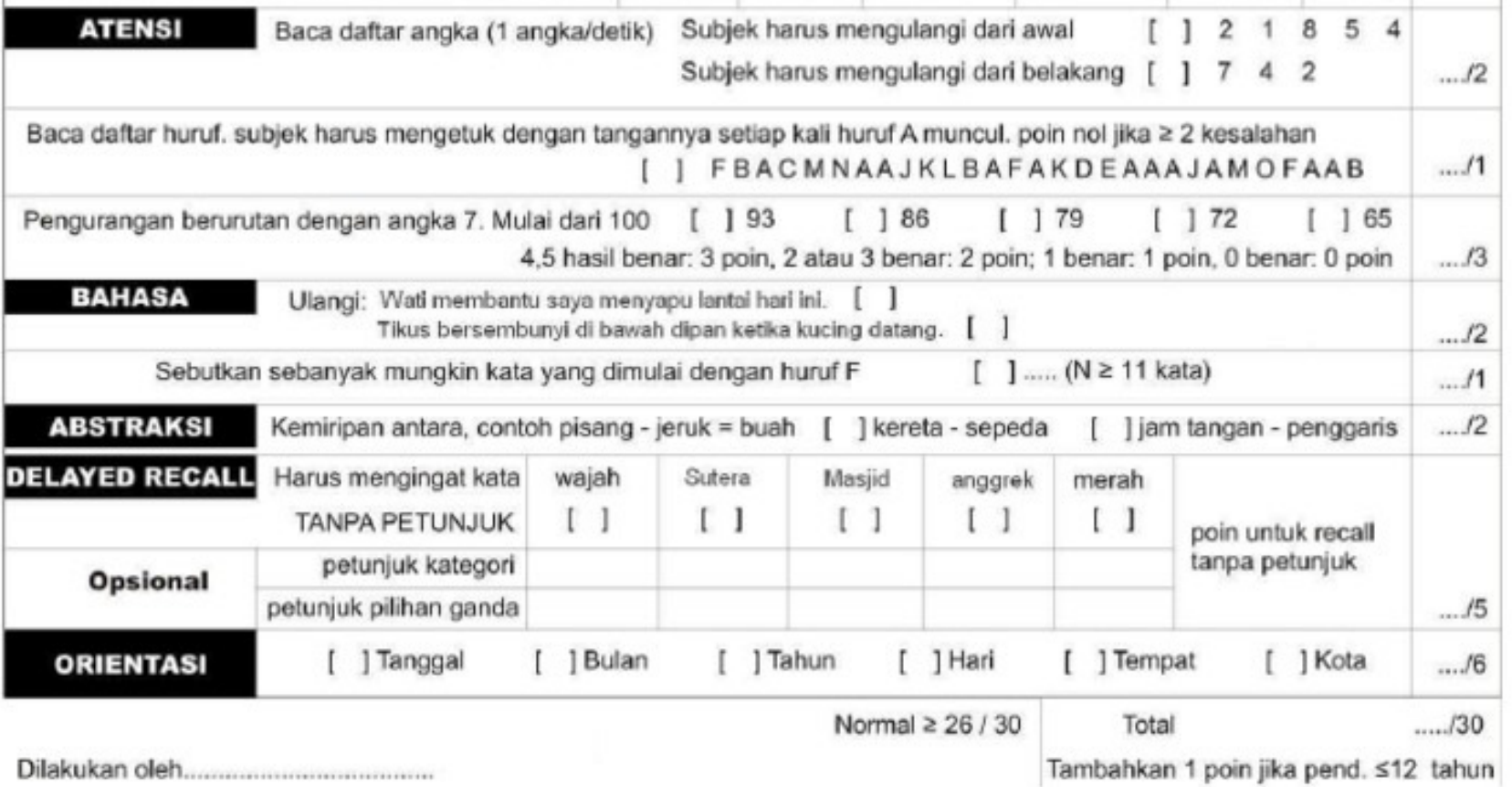

